A. Taran, I. Garkusha, V. Taran, R. Muratov, V. Starikov, A. Baturin, S. Romaniuk and A.G. Mamalis

\title{
Influence of plasma-based ion implantation and deposition on the structure, internal stress and mechanical properties of nanocrystalline $\mathrm{ZrN}$ coatings
}

\begin{abstract}
Nanocrystalline films of zirconium nitride have been synthesized using the plasmabased ion implantation and deposition (PBIID) technique on AISI 430 stainless steel at low substrate temperature. Structural, chemical and mechanical examination - using X-ray diffraction (XRD), scanning electron microscopy (SEM) with microanalysis (EDX) and nanoidentationwas undertaken to elucidate phase and chemical composition, surface morphology, microstructure and nanohardness of the $\mathrm{ZrN}$ coatings. The stressed state was studied by X-ray tensometry ( $a-$ $\sin ^{2} \psi$ method) and its modified variants applied to condensates with a strong axial texture. The maximal nanohardness was $44 \mathrm{GPa}$ with elastic modulus of $506 \mathrm{GPa}$. Some examples of medical instruments coated with $\mathrm{ZrN}$ are presented.
\end{abstract}

Keywords: coating, structure, vacuum-arc deposition, zirconium nitride

Nanotechnology Perceptions 16 (2020) 56-63

doi: 10.4024/N16TA19A.ntp.16.01 